\title{
PROTECGIÓN PATRIMONIAL DEL DERECHO DE IMAGEN EN AMÉRICA LATINA
}

\author{
Javier Berdaguer Mosca*
}

\begin{abstract}
Resumen
En el presente estudio se describen los tres principales modelos que se han elaborado en el derecho comparado para explicar la protección patrimonial del derecho de imagen (derecho de propiedad intelectual, derecho de la personalidad y derecho híbrido compuesto de facultades personales y patrimoniales). Luego se analizan los principales componentes de la regulación del derecho de imagen en América Latina, con especial énfasis en la forma de entender los actos de explotación patrimonial, para finalmente intentar conectar la realidad latinoamericana con los modelos teóricos ya existentes.
\end{abstract}

Palabras claves: Derecho de imagen, explotación patrimonial de los derechos de la personalidad, derecho comparado.

\section{Planteamiento de la cuestión}

El principio general es que a cada persona le corresponde la decisión de permitir (o no) a otro la utilización de su apariencia física reconocible, lo que se denomina normalmente como derecho a la propia imagen. ${ }^{1}$

Este derecho presenta una primera faceta, que se denomina personal o moral, concepto con el que se alude a una barrera jurídica de contención contra las intromisiones indebidas en la esfera individual, que normalmente se materializan en la captación y/o exposición pública indeseada e injustificada de la imagen de otro. El fundamento de esta protección radica en la necesidad de reconocer una amplia capacidad de autodeterminación en la forma en que cada uno quiere presentarse ante la sociedad, ${ }^{2}$ idea que está asociada con la protección de la dignidad humana. Todo acto que instrumente un atributo de la personalidad de otro como un objeto implica un avasallamiento de la personalidad de éste, ${ }^{3}$ salvo que dicha utilización esté justifi-

\footnotetext{
* Universidad de la República Oriental del Uruguay, Uruguay; Universidad Católica Dámaso Antonio Larrañaga, Uruguay (jberdaguer@guyer.com.uy). Artículo recibido el 17 de junio de 2019, y aceptado para su publicación el 6 de agosto de 2019 .

1 Cabe aclarar, aunque no lo vamos a desarrollar aquí, que actualmente el ámbito de protección del derecho de imagen es más amplio que la apariencia física, pues incluye todas las manifestaciones externas de la identidad de la persona física como su voz, nombre y otras características que la identifican públicamente o en un círculo determinado: Cabanellas de las Cuevas (2014), p. 168.

2 Whitman (2004), p. 1160 y ss. Resta (2011), pp. 49-50; Resta (2014), pp. 21-23;

3 Zavala (2011), p. 4.
} 
cada por el consentimiento de la persona retratada o se trate de un supuesto en que existe un permiso legal. ${ }^{4}$

Sin embargo, el análisis del derecho de imagen sería incompleto si no tomara en cuenta que, al mismo tiempo, es un fenómeno frecuente que las personas realicen actos de explotación patrimonial sobre la imagen de otros. Es cierto que no se trata de un fenómeno novedoso, pues los primeros casos de jurisprudencia sobre el derecho de imagen estuvieron relacionados con su utilización publicitaria. ${ }^{5}$ Más aun, ya a fines del siglo XIX comenzó a considerarse que la fama de una persona (y los signos que identifican a esa persona frente a todos, como su nombre o su imagen) es una fuerza atractiva que se presta bien para la explotación comercial. ${ }^{6}$ En algunos casos, esta utilización de la imagen con fines comerciales es realizada con el consentimiento de la persona en cuestión y a cambio de sumas que llegan a ser astronómicas, lo que condujo a que la imagen adquiera, junto con la faceta moral, una faceta patrimonial que la hace tornarse en un bien transable en el mercado. ${ }^{7}$ De tal manera que esta faceta también captura los actos dirigidos a aprovecharse económicamente de la imagen de una persona, entendiéndose que prima facie los frutos de esa actividad deben corresponder en exclusiva a la persona cuya imagen es utilizada. La imagen puede volverse así objeto de negocios jurídicos, en tanto que permite a la persona titular del derecho rentabilizar el valor de mercado que genere la explotación de su imagen. ${ }^{8}$ El derecho de imagen opera como un instrumento para alocar la utilidad económica generada por la explotación de la imagen en beneficio de su titular, quien resulta investido de un monopolio de explotación económica sobre su imagen, en forma similar a la que opera el derecho de propiedad respecto de los frutos de la cosa. ${ }^{9}$

La respuesta brindada en la mayoría de los ordenamientos ha sido otorgar alguna clase de protección a esta dimensión patrimonial del derecho de imagen. En particular, la reacción normal de la jurisprudencia ha sido favorable a defender a la persona retratada contra los actos de terceros que se han apropiado del valor patrimonial de su imagen sin haberle pedido permiso, censurando a quienes, con fines comerciales, pretendan llevar a cabo una "vuelta gratis". Es particularmente ostensible la protección de carácter patrimonial cuando los tribunales conceden al reclamante una indemnización fijada sobre la base del precio que razonablemente hubiera sido

4 Se admite en todas las jurisdicciones que existen supuestos en que la utilización de imagen ajena debe considerarse justificada, aunque no se haya obtenido el consentimiento de la persona retratada, cuando dicha utilización concreta sea realizada sin abuso (dentro de ciertos límites y en forma que no sea innecesariamente lesiva), y sobre todo cuando se evidencie que el demandado haya servido a un fin de interés público en la utilización de esa imagen.

5 Caso Rachel (Trib. Giv de la Seine, 1858). Vendrell (2014), pp. 50-51; Beverley et al (2005), pp. 1 y 147; en Estados Unidos: Rothman (2018), p. 11.

6 Beverley et al (2005), p. 1

7 Resta (2005), p. 238; Resta (2006), pp. 636 y 637; Loiseau (1997), p. 328; Priens (2006). Respecto de la comodificación: Resta (2011), pp. 41 y ss.

8 Vendrell (2014), pp. 202 y 203.

9 Resta (2005), p. 163. 
abonado por el demandado, si este hubiera pedido la autorización correspondiente (criterio de la regalía hipotética o de la licencia hipotética). ${ }^{10}$

Ahora bien, si miramos con mayor detalle por debajo de este consenso general, se pueden reconocer al menos tres distintos modelos en cuanto al alcance de esta protección patrimonial del derecho de imagen. Se trata de esquemas de ideas y creencias afines, que son comunes y que orientan la regulación en un determinado sentido. ${ }^{11}$ El análisis comparativo es muy útil para perfilar estos modelos. Afortunadamente, un análisis de este tipo ya ha sido abordado por varios autores y ello se ha hecho, por lo general, con elogiosa profundidad y buen criterio. ${ }^{12}$ Ahora bien, esta línea de pensamiento ha tomado como puntos de referencia a las jurisdicciones de Europa Occidental y los países del common law. En tal sentido, son casi inexistentes los análisis sobre la explotación económica de los derechos de la personalidad que incluyan una visión del conjunto de legislaciones de América Latina. ${ }^{13}$ Pensamos que se trata de una carencia a la que conviene ponerle fin. ${ }^{14}$

Por ello, lo que nos proponemos es apoyarnos en los antecedentes doctrinarios que han emprendido el análisis comparativo ${ }^{15}$, haciendo de ellos nuestro marco teórico, para volcarnos con esa perspectiva a abordar el panorama de la regulación del derecho patrimonial sobre la propia imagen en los países de América Latina, con especial énfasis en la forma de entender los actos de disposición (contractual, o más ampliamente, negocial) sobre el derecho de imagen ${ }^{16}$. En última instancia, se trata de saber si es posible conectar a los países latinoamericanos con la teoría ya construida en el derecho comparado.

10 Este mecanismo implica la restitución del valor apropiado por el infractor: BEverLeY et al (2005), p. 69); Resta (2005), pp. 157 y ss.

11 Para desarrollo de los modelos de protección: Resta (2005), pp. 271-276; Beverley et al (2005), pp. 212-214; Resta (2006), pp. 635 y ss.; Black (2011), pp. 12-27; RESTA (2011), pp. 48-51 y 58-65; Vendrell (2014), pp. 461 a 465; Resta (2014), pp. 23 a 26.

12 Para una comparación entre Estados Unidos y algunos países de Europa, o entre países europeos: Whitman (2004), Beverley et al (2005), Bergmann (2009), Cantero et al (2010), Vendrell (2014). Para una comparación entre Estados Unidos y Reino Unido: LeAfFER (2007).

13 La única excepción es la obra de ANTEQUeRA (2012), que es más bien descriptiva y refiere únicamente al tratamiento del derecho de imagen en la jurisprudencia latinoamericana.

14 Un análisis comparativo de este tipo supone aceptar -como es nuestro caso- que los conflictos en torno a la explotación comercial del derecho de imagen son similares en todos los países, dado que también lo son las prácticas generales del mercado, y en particular el notorio avance de este último sobre sectores de la vida social que -hasta hace no mucho- le eran extraños. Siendo similares los problemas y su contexto, parece lógico que lo sean también las decisiones, o al menos las líneas directrices fundamentales que sirvan de guía para tomar esas decisiones.

15 En especial, los desarrollos de Giorgio Resta desde 2005.

16 Dejamos aclarado que no vamos a ingresar en el tratamiento jurídico de las intromisiones ilegítimas en el derecho de imagen y sus consecuencias que, en un sentido amplio, podrían ser consideradas como aspectos que integran el régimen de protección del derecho de imagen, sino que nos vamos a focalizar en los modelos de concebir los aspectos patrimoniales del derecho de imagen y la manera en que se explican los actos de disposición (contractual o negocial) sobre el derecho de imagen. 


\section{MARCO TEÓRICO}

La utilización comercial de los atributos de la personalidad humana plantea un dilema profundo entre el alcance de la protección de la personalidad y la facultad que se reconoce a toda persona de disponer eficazmente sobre su propia esfera patrimonial.

La doctrina comparada ha elaborado las bases para plantear que el tema de la explotación patrimonial del derecho de imagen puede reducirse y compactarse en torno a tres modelos de protección: (a) modelo basado en la existencia de dos derechos independientes, uno que tutela los aspectos personales y otro los patrimoniales, siendo ese último un derecho similar a la propiedad intelectual (modelo dualista), (b) modelo basado en un derecho de la personalidad (modelo monista) y (c) modelo híbrido (derecho único que contiene facultades personales y facultades patrimoniales, sin predominio de unas sobre otras). ${ }^{17}$ La existencia de distintos modelos se explica, fundamentalmente, por diferencias históricas y culturales. ${ }^{18}$

\subsection{Modelo dualista: derecho de propiedad intelectual}

El modelo estadunidense del right of publicity es calificado como "dualista" porque se fundamenta en la separación de dos derechos independientes: el derecho de privacidad (right to privacy) y el derecho de publicidad (right of publicity), siendo este último entendido como el derecho que cada persona tiene de controlar el uso comercial de su identidad (incluida su imagen). ${ }^{19}$

$\mathrm{El}$ right of publicity comienza a consolidarse como figura separada del derecho a la privacidad (del que deriva) en torno a $1950,{ }^{20}$ siendo un punto de quiebre para ello la decisión del Tribunal de Apelaciones del 2do. Distrito de $1953 .{ }^{21}$ Dicha decisión fue comentada por Nimmer, quien sentó las bases del nuevo derecho de propiedad que podía ser transferido y opuesto a los terceros. ${ }^{22}$ Si bien se trata de un derecho que fue diseñado para nacer en cabeza de las celebridades pertenecientes al star-system, la doctrina advirtió que nada se oponía a que pueda existir también en favor de cualquier persona. ${ }^{23}$

17 Supra nota 11.

18 Resta (2006), pp. 382 y ss.; Vendrell (2014), pp. 48 y ss.; Resta (2014a), pp. 75 y ss.; Resta (2014b), pp. 13 y ss.

19 Sobre la interesante evolución del right of publicity: Ma CARThy (2013), pp. 3 a 85; Rothman (2018), pp. 11 a 112.

20 Mc Carthy (2013), pp. 51 y ss. Sin embargo, las bases de este derecho venían gestándose desde varias décadas antes, como demuestra Rothman (2018), pp. 11- 29.

21 Haelan Laboratories, Inc. V. Topps Chewing Gum, Inc. (1953).

22 Nimmer (1954), pp. 209-210, 216 y 217. La relevancia del caso Haelan, así como también las motivaciones personales de Nimmer, han sido cuestionadas por Rothman (2018), pp. 50 y ss. También cabe destacar el influyente estudio de Prosser (1960).

23 Nimmer (1954), p. 217. 
A partir de la década del 1970, el right of publicity comenzó su etapa de expansión como un derecho de propiedad que recae sobre intereses distintos de la protección constitucional de la privacidad de las personas. ${ }^{24} \mathrm{Al}$ perfilarse de esta forma, cada vez se fue alejando más del requisito de demostrar la existencia de un daño moral o daño a los sentimientos del titular para que se considere configurado el hecho ilícito. ${ }^{25}$ En 1977 la Suprema Corte de Justicia de los Estados Unidos se pronunció favorablemente al right of publicity, ${ }^{26}$ trazando una analogía entre el right of publicity (al que definió como un derecho de cada persona a controlar la utilización y explotación comercial de su personalidad) y los derechos de propiedad intelectual. ${ }^{27}$ Este pronunciamiento generó que en las décadas siguientes se multiplicaran los artículos de doctrina y los casos de jurisprudencia sobre el tema, asumiendo un especial énfasis el tema de la transmisión mortis causa de este derecho de propiedad. ${ }^{28}$ En 1995 se aprueba el Restatement en materia de competencia desleal, dentro del cual se incluye la violación del right of publicity como parte del elenco del elenco de hechos ilícitos. ${ }^{29}$ Desde la década del 1990 a la actualidad, el right of publicity ha sido codificado en varios Estados a través de leyes estatales. ${ }^{30}$

Parece claro que el modelo dualista se presenta como un modelo favorable para promover el desarrollo del mercado de los derechos de imagen. Al asignarse a cada persona un derecho de propiedad sobre su propia imagen, ${ }^{31}$ la validez de cualquier acto de cesión dispositiva del derecho de imagen puede ser admitida como principio general, así como también la adquisición por el beneficiario de un derecho exclusivo bajo el cual se encuentra legitimado para accionar contra los terceros, lo mismo que la trasmisión mortis causa de tales facultades de explotación. ${ }^{32}$

Sin embargo, el modelo dualista no está exento de objeciones. Una de ellas es que no está nada claro que la protección conferida legalmente a la propiedad intelectual (por ejemplo, a las obras protegibles por el derecho de autor) pueda servir como un modelo teórico a utilizar para referirse a la protección de bienes que no son externos a la persona, sino que recaen sobre un aspecto inseparable de la persona misma, como lo es su imagen. ${ }^{33}$ Un desprendimiento absoluto del derecho de explotación de la propia imagen no parece razonable, pues una persona no debería quedar jurídicamente impedida de ejercer cualquier clase de control jurídico sobre la circulación

24 Mc СarThy (2013); pp. 64-65.

25 Mc Сarthy (2013), p. 67.

26 Zacchini v. Scripps-Howard Broadcasting Co., 433 U.S. 562 (1977).

27 Rothman (2018), pp. 76 y 80.

28 Rothman (2018), pp. 81-86.

291995 Restatement on the Law of Unfair Competition. Sección $§ 46$ y ss.

30 Mc Carthy (2013), p. 76. Rothman (2018, pp. 96 y ss.) destaca la disparidad de criterios que existen entre las legislaciones estatales y criterios de los tribunales de cada Estado.

31 Resta (2005), pp. 239-240.

32 Beverley et al (2005), p. 213.

33 Resta (2005), p. 332; Resta (2006), pp. 661-664; Rothman (2018), pp. 116, 126-128. 
de los atributos de su personalidad, o la asociación de los mismos con cualquier clase de producto o servicio. ${ }^{34}$ Por otro lado, también se ha objetado que existen dificultades para identificar el motivo que justifica la atribución de un derecho patrimonial independiente por el cual se confiere a la persona monopolio de explotación sobre su imagen, ${ }^{35}$ así como también existen dificultades para separar el caso en que estamos en sede de la utilización comercial de la imagen del que nos enfrenta a una utilización no comercial, ${ }^{36} \mathrm{o}$ las dificultades de concebir y gestionar el escenario en que este derecho patrimonial fuera objeto de embargo, de ejecución forzada por parte de los acreedores o de partición en caso de divorcio o extinción de la sociedad conyugal. ${ }^{37}$

\subsection{Modelo monista: derecho de la personalidad}

El modelo que se basa en la existencia de un derecho de la personalidad tiene arraigo en la Europa Continental. Frente a la ausencia de regulación en la mayoría de los códigos civiles del siglo XIX, la estrategia adoptada por la doctrina y la jurisprudencia ante los primeros casos consistió en delinear un derecho subjetivo de carácter absoluto entre el sujeto y sus atributos personales. ${ }^{38}$ En los comienzos se recurrió al derecho de propiedad, en tanto que arquetipo de derecho absoluto, ${ }^{39}$ con una tipología de bienes jurídicos que podían ser objeto de este derecho absoluto y que tenían la particularidad de ser internos a la persona. ${ }^{40}$ Desde el último cuarto del Siglo XIX, la doctrina alemana comenzó a construir la categoría de los derechos de la personalidad para explicar estos fenómenos. ${ }^{41}$ Si bien esta orientación puede explicarse por razones específicas de Alemania, ${ }^{42}$ el fruto de esos desarrollos tuvo un alcance enorme en varias jurisdicciones. ${ }^{43}$ Explicados como derechos absolutos que recaen sobre aspectos de la personalidad del sujeto, los derechos de la personalidad invisten a su titular de legitimación para reclamar por los daños y perjuicios causa-

34 Resta (2005), p. 333; Resta (2006), pp. 661-664; Rothman (2018), pp. 117 y ss.

35 Beverley et al (2005), p. 213; Bass (2008); MaCarthy (2013), pp. 87 y ss.; Rothman (2018), pp. 98-12.

36 Resta (2011), pp. 61 y 62; MaCarthy (2013), No 7: pp. 2 y ss.; Rothman (2018), pp. 138 y ss.

37 Resta (2011), pp. 64 y 65; Loiseau (1997), p. 344.

38 Resta (2014a), pp. 75 y ss.

39 Resta (2014b), pp. 13. Una parte de la dogmática francesa postulaba un derecho absoluto y exclusivo sobre la propia imagen, sin mayor referencia a su naturaleza, como Pouillet (1908), p. 243, mientras que otros lo calificaban como un derecho propiedad de cada persona sobre sí mismo: BEVERLEY et al, (2005), p. 148.

$40 \operatorname{Resta}(2011)$, p. 47

41 Resta (2005), pp. 422-451; Resta (2011), pp. 36-37; Resta (2014b), pp. 13-20; Cionti (2000), pp. 147 y ss.; VendRell (2014), p. 52.

42 Se menciona que en Alemania existía una posición restringida en cuanto a los objetos sobre los cuales puede existir un derecho patrimonial absoluto: RESTA (2014b), pp. 13 a 21.

43 Respecto del surgimiento y evolución de la teoría de los derechos de la personalidad en Alemania y el resto de Europa: Cionti (2000), pp. 147 y ss.; Resta (2005), pp. 43 y ss., 87 y ss.; Vendrell (2014), pp. 52 y ss.; ReSTA (2014b), pp. 14 y ss. 
dos por la invasión de terceros, sean éstos de carácter moral o patrimonial, así como también resultan idóneos para promover acciones dirigidas a la cesación de los actos ilícitos. ${ }^{44}$ Una vez construido el carácter absoluto (oponible erga omnes), resultó sencillo ponerlos en el carril de los remedios típicos de la responsabilidad extracontractual. ${ }^{45}$ La estructura básica del modelo personalista se encuentra en las siguientes ideas: estructura defensiva de los derechos de la personalidad, carácter extrapatrimonial de estos derechos, y la proclamación de la inalienabilidad de los mismos. ${ }^{46}$

La consideración del derecho de imagen como un derecho de la personalidad se desarrolló en Europa hasta lograr imponerse en forma generalizada a mediados del Siglo XX.$^{47}$ La instalación de este pensamiento vino de la mano de una cosmovisión iusnaturalista, o al menos desde una retórica exaltada sobre los aspectos personales en juego, que llevó desatender los aspectos patrimoniales que los derechos de la personalidad también tenían en su origen. ${ }^{48}$ Se produjo por esta época un fenómeno de "despatrimonialización" de los derechos de la personalidad, por medio de la cual se los concebía como un derecho "inherente a la personalidad humana", de carácter irrenunciable, indisponible e intransmisible, quedando por consiguiente silenciada o directamente rechazada la posibilidad de que estos derechos pudieran ser objeto de negocios jurídicos patrimoniales, ya sea por parte de sus titulares o por terceros. ${ }^{49}$ Este fenómeno explica la inclusión del derecho de imagen dentro del elenco de disposiciones relativas a la protección de la personalidad en la parte general de varios códigos civiles del siglo XX, como el Código Italiano de 1942 (art. 10), la reforma del Código Civil de Portugal de 1966, la Ley Francesa de 1970, o en leyes específicas que tratan al derecho de imagen como un derecho de la personalidad, como la Ley Orgánica Española de 1982.

Una de las objeciones que se han hecho contra este modelo es que asienta una protección meramente defensiva (basado en la responsabilidad extracontractual), siendo este enfoque insuficiente para resolver diversas cuestiones que en la actualidad han cobrado gran relevancia práctica y que exigen una definición más precisa del contenido y la naturaleza de la dimensión patrimonial del derecho de imagen. Se

44 Resta (2005), pp. 115 y 118.

45 Resta (2005), pp. 125, 182-183; Resta (2011), pp. 33-34; Vendrell (2014), p. 55.

$46 \operatorname{Resta}(2011)$, p. 37. Considerando al derecho sobre la imagen como un derecho de la personalidad, la doctrina alemana concluía que se trata de un derecho inalienable, y por consiguiente no puede ser cedido: RESTA (2005), pp. 118 y ss.; BEvERLEY et al (2005), p. 130. Sin embargo, resulta admisible el otorgamiento de un permiso, al que se lo consideraba como un mero acto de legitimar una intromisión ajena, ya sea bajo el adagio volenti non fit injuria (el consentimiento de la víctima excluye la ilicitud), o bien bajo la forma de un pactum de non petendo (obligación de abstenerse de reclamar por los actos de intromisión autorizados). VENDRELL (2014), pp. 224 - 264.

47 Resta (2014b), p. 3. Las posiciones más influyentes: Francia: NERson (cit por BeVERLey et al, 2005, pp. 150 y 151); Italia: De Cupis (1950), p. 29 y Vercellone (1959), pp. 26 y ss.; España: De Castro (1959).

48 Resta (2005), pp. 124-125, 182-183; Pino (2003), pp. 10, 12-13; Vendrell (2014), pp. 55-59, quien bautizó este fenómeno como la "expulsión de los mercaderes del templo de los derechos de la personalidad".

49 Resta (2005), pp. 126-127; Pino (2003), pp. 15 y 16; Vendrell (2014), p. 60. En lo que refiere a Francia: Castaldi (2008), p. 7; SERna (1997), pp. 94 y 138. 
alude así a los intereses de personas distintas del titular originario y que pretenden ser tutelados en la explotación de la imagen de éste, ya sea porque obtuvieron su autorización exclusiva, o porque se trata de sus herederos o sucesores, y que aspiran a un grado aceptable de certeza en la posibilidad de promover acciones contra otros terceros, e incluso contra el mismo titular (si realiza actos que implican un incumplimiento de los pactos ya asumidos).

\subsection{Modelo intermedio: derecho híbrido}

El tercer modelo disponible es, en realidad, una evolución de la teoría basada en el derecho de la personalidad que venimos de mencionar. En efecto, en torno a la década de 1980, se produjo en Europa Continental un nuevo movimiento del péndulo, esta vez dirigido hacia el impulso del mercado de los derechos de imagen. El fenómeno de la comodificación de la personalidad excede al derecho de imagen y alude a que la lógica del mercado va alcanzando todos los aspectos de la vida de la persona, tanto corporales (organismos, tejidos, gametos, ADN) como incorporales (nombre imagen, voz, datos personales), los cuales son tratados como bienes que pueden ser comprados, vendidos o licenciados..$^{50}$ Este fenómeno desafía cualquier entendimiento que se instale cómodamente sobre una supuesta incompatibilidad entre los derechos de la personalidad y la explotación de los intereses económicos, e invita a los juristas a pensar seriamente las cuestiones relacionadas con la disposición, enajenación y transferencia de estos derechos, que fueron subestimadas durante buena parte del siglo XX. ${ }^{51}$ El incremento del volumen de negocios sobre el derecho de imagen, lo mismo que el aumento de las cantidades en juego, hicieron imperioso poner mayor énfasis en la explotación de los valores comerciales de la personalidad, puesto que una concepción que se desentienda totalmente de esos aspectos trae consigo dejar a los terceros en una posición de debilidad jurídica frente al propio cedente/autorizante en el marco de la contratación comercial sobre el derecho de imagen, así como contra los terceros, incrementando los costos de transacción. ${ }^{52}$

Ahora bien, este avance de la lógica del mercado no implicó que la dogmática europea se viera forzada a desarmar la tradicional categoría de los derechos de la personalidad ${ }^{53}$ sino que los tribunales recurrieron a técnicas de interpretación dinámica para adaptar las viejas disposiciones sobre el nombre, la imagen o la privacidad para un panorama cambiante en lo social y lo económico. ${ }^{54}$ Se ha favorecido así una evolución funcional de los derechos de la personalidad, en lugar de un cambio de paradigma radical que implique pasar a un modelo basado en un derecho patrimonial independiente, como el right of publicity. ${ }^{55} \mathrm{El}$ caso es que las disposiciones relativas a protección del nombre, la imagen u otros datos personales, nunca impidieron

\footnotetext{
50 Resta (2011), p. 42.

51 Resta (2011), pp. 42-43

52 Beverley et al (2005, p. 212); Vendrell (2014), pp. 152-160 y 402.

53 Resta (2011), p. 49; Resta (2014b), pp. 11-12.

54 Ídem.

55 Ídem.
} 
textualmente el uso de los remedios típicos para proteger intereses económicos. ${ }^{56}$ De hecho, el modelo de protección adoptado por Alemania en la Ley de Derechos de Autor de 1907, la Ley Italiana de 1925 (y luego Ley de Derechos de Autor de 1942), en forma coincidente con la jurisprudencia francesa (que concibe al derecho de imagen como un derecho absoluto), reproducen el paradigma típico de las reglas del derecho de propiedad, admitiéndose ampliamente la posibilidad de recurrir a ejecución forzada y recuperación de daños causados por el uso no consentido de la identidad. ${ }^{57}$

Esta corriente intermedia explica que nos encontramos ante un derecho híbrido sobre la propia imagen, que tiene una naturaleza proteica, puesto que se compone de facultades morales y facultades patrimoniales. ${ }^{58}$ Por otro lado, se ha realizado un considerable esfuerzo en que esta construcción permita otorgar una protección adecuada a los dos aspectos del derecho de imagen.

En lo que refiere a las facultades patrimoniales, la posición de los adquirentes de buena fe y el desarrollo del mercado no se ve necesariamente afectada por no tratar este derecho como un derecho de propiedad, en tanto que es posible sostener que los actos de explotación económica queden encuadrados como actos de concesión o disposición constitutiva que recaen sobre las facultades patrimoniales de explotación, por medio de los cuales se constituye un derecho en el patrimonio ajeno que va a convivir con el derecho que se mantiene en cabeza del concedente. ${ }^{59}$ La categoría de los actos de concesión o sucesión constitutiva presenta menor intensidad que la correspondiente a los actos de enajenación o sucesión traslativa, porque no supone la pérdida de titularidad de las facultades que se desplazan a otro,${ }^{60}$ de manera que el titular originario (persona de cuya imagen hablamos) permanece vinculado con la explotación de los atributos de su personalidad en la medida en que sigue siendo titular del derecho matriz, del que se desprenden los derechos de explotación. ${ }^{61}$

No obstante, la necesidad de contar con una red de protección para los intereses personales que están en juego cuando se contrata sobre bienes de la personalidad nos hace volver la vista hacia el régimen ordinario de los contratos. ${ }^{62}$ Se trata de postular un compromiso que sea aceptable en cuanto a la libertad que se reconoce para el ejercicio de la autonomía privada en materia contractual y la protección de la dignidad humana y la preservación de la autodeterminación que rigen la protección

56 Resta (2011), p. 49

57 Resta (2011), pp. 49-50; Resta (2014b), p. 23

58 Resta (2005), pp. 242-247

59 VENDRELL (2014), p. 467.

60 Resta (2005), pp. 334-345; Resta (2006), pp. 661-664; Vendrell (2014), pp. 99 y ss., 139 y ss.

61 VendReLl (2014), p. 467.

62 Resta (2011), p. 61. Vendrell, en cambio, ensaya para España la separación de dos derechos distintos, siendo el derecho patrimonial sobre la imagen el que podría ser objeto de actos de concesión (más no de transferencia) que atribuyen al beneficiario un derecho absoluto oponible frente a terceros: VENDRELL (2014), pp. 451 a 471. 
de los atributos de la personalidad. ${ }^{63}$ A efectos de plantear las bases de este compromiso, la doctrina europea ha señalado algunos puntos principales que deben tenerse en cuenta: (i) la aplicación de un principio de especificidad en materia de consentimiento otorgado, como el que rige en materia de consentimiento para el tratamiento de los datos personales, de manera que solo se consideran autorizadas las utilizaciones de la imagen específicamente autorizadas ${ }^{64}$ la manifestación de autorización debe asumir un carácter puntual y ser expresa, no resultando válida la autorización genérica y omnicomprensiva; ${ }^{65}$ (ii) un criterio de interpretación estricta en materia de derecho de imagen, tal como regularmente se aplica en materia de transferencia de derechos de autor y se aplica por los tribunales en materia de derecho de imagen; ${ }^{66}$ de esta manera, la autorización debe considerarse restringida en sentido objetivo y subjetivo a los actos mencionados, o bien a los usos previsibles al momento de otorgarse el consentimiento, ${ }^{67}$ y (iii) la admisibilidad de un derecho de retirar el consentimiento ya otorgado (derecho de receso unilateral o revocación), incluso sin reconocimiento expreso, aunque bajo el requisito de indemnizar los daños y perjuicios causados. ${ }^{68} \mathrm{~A}$ lo anterior cabe agregarse la convicción generalizada acerca de que el régimen de publicaciones libres (permiso legal para utilizar la imagen ajena sin consentimiento) debe ser interpretado en forma restrictiva, no resultando aplicable a los casos de utilización comercial o con fin de lucro, en tanto que en ese caso se presume la ilicitud a menos que el demandado acredite que ha obtenido el consentimiento. ${ }^{69}$

\section{EL DEREGHO DE IMAGEN EN AMÉRIGA LATINA}

\subsection{Panorama general}

La mayoría de los países de América Latina carecen de una sistematización legislativa sobre el derecho de imagen. ${ }^{70}$ No obstante, existen algunas disposiciones parciales de derecho positivo, las que han sido utilizadas por la doctrina y jurisprudencia para construir un aparato dogmático que permita hacer frente a los conflictos que, en forma cada vez más creciente, da lugar el aprovechamiento comercial del derecho de imagen.

\footnotetext{
63 Resta (2011), p. 61.

64 Resta (2011), p. 63.

65 Resta (2005), pp. 285 - 292; Resta (2006), pp. 646-650.

66 Resta (2011), p. 63.

67 Resta (2005), pp. 292 - 297; Resta (2006), pp. 650-653; Resta (2014a), p 119.

68 Resta (2005), pp. 298 - 307; Resta (2006), p. 653-659; Resta (2011), p. 64; RESTA (2014a), pp. 117 121; RESTA (2014b), p. 25.

69 Resta (2005), pp. 146, 155 y 281.

70 Cabanellas de las Guevas (2014), p. 172.
} 


\subsubsection{La doble dimensión del derecho de imagen}

Uno de los aspectos más destacables es el reconocimiento generalizado acerca de que el derecho de imagen presenta dos dimensiones o vertientes, una personal y otra patrimonial..$^{71}$ La tesis del doble contenido ha sido desarrollada particularmente en la doctrina de Argentina, ${ }^{72}$ Brasil,${ }^{73}$ Chile,${ }^{74}$ Colombia, ${ }^{75}$ México $^{76}$ y Uruguay ${ }^{77}$ Asimismo, existe reconocimiento a la misma en la jurisprudencia de varios países latinoamericanos, como Brasil ${ }^{78}$ Chile,${ }^{79}$ Colombia ${ }^{80}$ y República Dominicana. ${ }^{81}$

\subsubsection{Dimensión personal del derecho de imagen}

En lo que refiere a la vertiente personal, la misma aparece normalmente asociada a la protección constitucional del derecho a la propia imagen. En tal sentido, debe destacarse que el derecho de imagen ha sido expresamente incluido dentro del elenco constitucional de derechos fundamentales o derechos inherentes a la persona humana en el caso de Bolivia, ${ }^{82}$ Brasil, ${ }^{83}$ Ecuador, ${ }^{84}$ El Salvador, ${ }^{85}$ Honduras, ${ }^{86}$ Paraguay, ${ }^{87}$ Perú, ${ }^{88}$ República Dominicana ${ }^{89}$ y Venezuela.$^{90}$ Consistentemente, los tribunales de estos países lo han calificado como un "derecho humano" (...) "originado en la

71 ANTEQUera (2012), pp. 400 a 403.

72 Cabanellas de las Cuevas (1998), p. 450; Villalba (2006); Picasso (2007), pp. 40 y 41; Márouez y Calderón (2009), p. 105; Cabanellas de las Cuevas (2014), pp. 174 y 175; Villalba (2015), pp. 93 y 99.

73 Rodrigues (2009), p. 127; Rodrigues da Cunha e Gruz (2013), p. 364; Bortolan y Pascoaloto (2014), p. 3104; Glitz y BORTOLAn (2017), pp. 362 y 363; BorTOLAn (2018), p. 739;

74 Nogueira (2007), pp. 262, 266-270, 274; Larraín (2016), pp. 131-132, 162 y 169; Aillapán (2016), pp. 446 y 447; FERRANTE (2017), pp. 148 y 149.

75 Ceballos (2011), p 68; GuZmán (2016), p. 58.

76 Flores (2006), pp. 381 y 382; Alatriste (2013), p. 36, Arroyo (2015), p. 85.

77 Yglesias (1987), p. 20; Balsa (2001), pp. 19, 20, 22, 27-29 y 47; Lamas (2004), pp. 37-39, 46, 225 y ss.; HOWARD (2008), p. 178.

78 Entre otras: Superior Tribunal de Justicia: 23/02/99, 25/10/99. 14/03/2000 y 18/05/2000.

79 Caroca Rodríguez Christian Antonio contra Electrónica Sudamericana Limitada (2009); Corte de Apelaciones de Santiago: 24/03/2009.

80 Corte Constitucional de Colombia: 1998 y 2016.

81 Juzgado de Primera Instancia del Distrito Nacional (2008) y Corte de Apelación del Distrito Nacional (2009).

82 Const. 2009, art. 21.2.

83 Const. 1988, art. 5, literales V y X.

84 Const. 2008, art. 66.18.

85 Const. 1983, art 2.

86 Const. 1982, art. 76.

87 Const. 1992, arts. 25 y 33.

88 Const. 1993, art. 2.7.

89 Const. 2010, art 44.

90 Const. 1999, art 60. 
dignidad humana", ${ }^{91}$ por ser una "emanación de la propia persona", ${ }^{92}$ como "garantía y libertad de la persona humana", ${ }^{93}$ o bien como un "derecho fundamental de la personalidad, formando parte de los derechos civiles esencialmente individuales que tiene la persona en virtud de su condición de ser humano". ${ }^{94}$

No obstante, aquellos países que no cuentan con una disposición constitucional expresa, han entendido de todas formas que la protección constitucional es implícita, ya sea como parte de la protección de la privacidad o dignidad de la persona o, más genéricamente, como una emanación inherente de su personalidad. En tal sentido, puede citarse la jurisprudencia de Argentina, ${ }^{95}$ Chile, ${ }^{96}$ Colombia, ${ }^{97}$ Costa Rica, ${ }^{98}$ Puerto Rico, ${ }^{99}$ México ${ }^{100}$ y Uruguay. ${ }^{101}$

Por fuera de la protección constitucional, cabe destacar que varios países han reconocido al derecho de imagen como un derecho de la personalidad dentro de sus Códigos Civiles, así como en leyes especiales. Este es el caso de Argentina, ${ }^{102}$ Bolivia, ${ }^{103}$ Brasil, ${ }^{104}$ Costa Rica, ${ }^{105}$ México, ${ }^{106}$ Panamá, ${ }^{107}$ Perú ${ }^{108}$ y Puerto Rico. ${ }^{109}$

91 Tribunal Constitucional de Bolivia: 25/08/2004.

92 Tribunal Superior de Justicia de Brasil, Sentencia del 15/09/1997, cit. por AnteQuera (2012), p. 379.

93 Tribunal de Justicia del Estado de San Pablo, Segunda Cámara de Derecho privado, Sentencia del 28/09/2010, cit. por ANTEQUera (2012), p. 379.

94 Tribunal Supremo de Justicia de Venezuela, Sent. Sala Constitucional del 3/10/2002, cit. por Antequera (2012), p. 379.

95 Corte Suprema de Justicia de la Nación: 11/12/1984, 15/04/1993, 11/12/2007, 25/09/2001, 12/09/2017.

96 Corte Suprema: 9/09/1997. Esta jurisprudencia ha sido desarrollada en varias sentencias que siguieron: LARRAÍn (2016), pp. 129 y ss. La doctrina chilena ha realizado esfuerzos por fundamentar que el derecho de imagen se encuentra implícitamente reconocido por la misma: NogueIRA (2007) y Larraín (2016), pp. 148 y 149. Para una visión crítica al respecto: Ferrante (2017).

97 Corte Constitucional de Colombia: 6/03/1996, 6/07/1999 y 24/05/2007.

98 Corte Suprema de Costa Rica: 1/11/2005, cit. por ANTEQuera (2012), p. 379.

99 Tribunal Supremo de Puerto Rico: 1982, 1996 y 2008.

100 Suprema Corte de Justicia de la Nación: 6/01/2009, cit. por ANTEQUERA (2012), p. 380.

101 Tribunal de Apelaciones en lo Civil: 5/12/97, 20/2011, 20/02/2012.

102 Código Civil y Comercial de la Nación (2014), art. 253.

103 Código Civil (1975), art. 16.

104 Código Civil (2002), art. 20.

105 Código Civil (1996), arts. 47 y 48

106 Ley (2006), arts. 16 y ss.

107 Código de Familia (1994), arts. 575 y 577.

108 Código Civil (1984), art 15.

109 Ley de fecha 13/07/2011. 
En las últimas décadas -y en particular después del año 2000- se han propagado a lo largo de América Latina las leyes de protección de datos personales. Se trata por lo común de cuerpos de disposiciones bastante extensos y detallados, dictados bajo una fuerte inspiración en el derecho comunitario europeo sobre dicha materia. Este aspecto tiene relevancia para nuestro tema, puesto que la definición de "dato personal" es sumamente amplia, lo suficiente para incluir dentro de este sector a la imagen cada persona. En esta línea pueden mencionarse, entre otras, la ley argentina del año 2000, la ley chilena de 1999, la ley uruguaya de 2008, la ley federal de México de 2010, la ley peruana de 2011 y la ley colombiana de 2012. Estas leyes por lo general imponen una regulación del tratamiento de los datos personales que parte de la consideración de éstos como un derecho inherente a la persona, lo que impacta en varios puntos de la regulación, como ser (sin pretender una enumeración exhaustiva). disposiciones particulares (y muy exigentes) en materia de los requisitos que debe tener el consentimiento del titular de los datos para que pueda llevarse a cabo cualquier "tratamiento" de los mismos, disposiciones que limitan el tratamiento únicamente a las finalidades que hayan sido informadas y consentidas por escrito por el titular, creación de organismos administrativos con la finalidad de vigilar el cumplimiento de la normativa, creación de acciones específicas dirigidas a indagar, modificar y revocar cualquier autorización dada por el titular para el tratamiento de los datos personales por un tercero.

\subsubsection{Dimensión patrimonial del derecho de imagen}

La dimensión patrimonial del derecho de imagen tuvo un reconocimiento temprano en el derecho positivo de los países de América Latina. Si bien los Códigos Civiles del siglo XIX tomaron como fuente de inspiración los códigos civiles europeos (y en particular el Código Civil de Napoleón) -y, por consiguiente, no contenían una regulación específica sobre los derechos de la personalidad, ni sobre el derecho de imagen-, el reconocimiento de la vertiente patrimonial vino de la mano de las leyes sobre propiedad literaria y la protección dada al retrato. Las primeras leyes que se dictaron en este sentido datan de la primera mitad del siglo XX, entre las que cabe citar el Código Civil brasilero de 1916, ${ }^{110}$ y las leyes de propiedad literaria de Argentina, ${ }^{111}$ Uruguay, ${ }^{112}$ Colombia ${ }^{113}$ y Paraguay. ${ }^{114}$ En el tratamiento dado a la explotación del retrato en todas estas primeras manifestaciones es notoria la influencia de la Ley de Derechos de Autor de Alemania 1907 (todavía vigente) y de la ley italiana de 1925 (sustituida por la ley de 1942).

Al día de hoy, la mayoría de países de América Latina cuentan con disposiciones relativas al derecho de imagen dentro de sus leyes sobre derechos de autor. Además de las legislaciones de Argentina de 1933 y Uruguay de 1937 ya mencio-

110 Código Civil (1916) Art. 666, Nº X (derogado a la fecha).

111 Ley (1933), arts. 31 a 35 (vigente a la fecha).

112 Ley (1937), art. 21 (vigente a la fecha).

113 Ley (1946), arts. 25 a 27 (derogada a la fecha).

114 Ley (1951), arts. 29, 31 y 32 (derogada a la fecha). 
nadas (y que siguen vigentes), puede citarse el caso de Brasil ${ }^{115}$, Colombia ${ }^{116}$, Costa Rica $^{117}$, Ecuador ${ }^{118}$, El Salvador ${ }^{119}$, Guatemala ${ }^{120}$, Honduras ${ }^{121}$, México ${ }^{122}$, Panamá ${ }^{123}$, Paraguay $^{124}$, Perú ${ }^{125}$ y República Dominicana ${ }^{126}$. La regulación del derecho de imagen en estas leyes es por lo general escueta, pero de gran aplicación práctica. Se trata de un paréntesis breve (entre uno y tres artículos) en el cual se aclara que la explotación comercial de la obra pictórica, escultórica o fotográfica que contiene la imagen de una persona (retrato, busto, escultura o fotografía) requiere, además del consentimiento del autor de dicho retrato, el consentimiento de la persona retratada. En la mayoría de estas legislaciones el consentimiento de la persona retratada es requerido para "poner en el comercio" su retrato ${ }^{127}$, mientras que también se recurre a otras formas equivalentes como "exhibir o exponer en el comercio el busto o el retrato"128, "utilizar el busto o el retrato con fines de lucro"129, "comerciar, publicar, exhibir o exponer la imagen de una persona"130, "aprovecharse de la imagen y la voz"131 "utilizar la fotografia"132, o "usar o publicar el retrato"133. Más allá de las variantes de redacción, en todos estos casos el legislador ha exigido obtención del consentimiento de la persona retratada (titular del derecho de imagen) para la utilización comercial de su imagen, lo que implica un reconocimiento expreso de la dimensión patrimonial de este derecho.

Fuera de la sede de los derechos de autor y de los códigos civiles, existen algunas referencias particulares a la explotación económica del derecho de imagen. ${ }^{134}$

115 Ley (1998), art. 46, lit. c

116 Ley (1982), art. 87.

117 Ley (1982), art. 178.

118 Ley (2016), arts. 160 y 161.

119 Ley (1993), art. 38.

120 Ley (1998), arts. 39 y 69.

121 Ley (1999), art. 60.

122 Ley (1996), art. 87.

123 Ley (2012), art. 37.

124 Ley (1998), art. 78.

125 Ley (1996), art. 85.

126 Ley (2000), arts. 36, 52 y 53.

127 Argentina (1933), art. 31; Ecuador (2016), art. 160; El Salvador (1993), art. 38; Honduras (1999), art. 60; Perú (1996), art. 85; Paraguay (1998), art. 78, Panama (2012), art. 37; Uruguay (1937), art 21.

128 Colombia (1982), art. 87; Costa Rica (1982), art. 178; República Dominicana (2000), art. 52.

129 Guatemala (1998), arts. 39 y 69; Brasil (2002), art. 12.

130 Bolivia: Ley (1975), art. 16.

131 Perú (1984), art. 15.

132 Ecuador (2016), art. 161.

133 México (1996), art. 87.

134 Por ejemplo, en normas relativas al contrato de trabajo, regulación de la publicidad, normativa sobre protección de menores y adolescentes, Código Penal. AnTequera (2012), pp. 380-381. 
Entre las disposiciones especiales cabe destacar las leyes sobre el derecho a la propia imagen que se dictaron en México ${ }^{135}$ y Puerto Rico, ${ }^{136}$ en tanto que incluyen una regulación más compleja y detallada sobre aspectos patrimoniales de la utilización de la imagen ajena. También se destaca la ley brasilera de 1998 (conocida como "Lei Pelê"), que al tiempo que incluye la regulación del "derecho de arena" a favor de las entidades organizadoras de espectáculos deportivos, reconoce por otro lado a los deportistas que participen en espectáculos televisados (a quienes se considera explícitamente como titulares de un derecho de imagen) un derecho de remuneración equivalente al 5\% de los ingresos que se reciban por la explotación de los derechos audiovisuales ${ }^{137}$.

\subsection{Los modelos de protección patrimonial del derecho de imagen}

A continuación vamos a analizar más de cerca los conceptos vertidos por la doctrina y jurisprudencia nacionales sobre los actos (ya sea contractuales, o en forma más amplia, negociales) por medio de los cuales se instrumenta la explotación económica del derecho de imagen. Por razones de espacio, únicamente nos referiremos a algunas jurisdicciones y no a todas.

\subsubsection{Argentina}

La doctrina y la jurisprudencia han venido considerando desde hace tiempo que el derecho de imagen forma parte de los "derechos personalísimos". ${ }^{138}$ De conformidad con ello, se parte de que existe un principio general por el que se considera ilícita la utilización de la imagen ajena sin autorización, sin requerir que se trate de una utilización comercial. Mientras la única disposición de derecho positivo sobre el tema era la ley de derechos de autor, se interpretaba que la expresión "poner en el comercio" en un sentido amplio, incluyendo cualquier utilización de la imagen ajena. ${ }^{139}$ La calificación como derecho personalísimo no ha impedido que se admita plenamente la posibilidad de explotar económicamente el derecho de imagen mediante negocios jurídicos. ${ }^{140}$ Sin embargo, estos actos son caracterizados generalmente como negocios de autorización, o bien como actos que tienen por cometido eliminar la ilicitud de la intromisión en un derecho considerado como "relativamente indisponible". ${ }^{141}$ En cambio, se niega la validez de un negocio de cesión o transfe-

135 México (2006).

136 Puerto Rico (2011).

137 Lei Pele (1998), art. 42.

138 Cabanellas de las Cuevas (2014), p. 174.

139 Villalba y Lipszyc (2009), p. 66; Márquez y Galderón (2009), p. 107; Cabanellas de las Guevas (2014), p. 187. Tampoco se requiere para la procedencia de la acción de responsabilidad la intención maliciosa, la perdida de clientela, la invasión a la privacidad, sino tan solo la verificación de un perjuicio indemnizable, que puede ser moral o patrimonial: Cabanellas de las Guevas (2014), p. 187.

140 Villalba (2006), Gorosito (2007), pp. 260 y ss. Márouez y Calderón (2009), p. 107; Cabanellas de las Cuevas (2014), p. 169.

141 Villalba y Lipszyc (1980), p. 817; Cifuentes (2008), pp. 170-171; Zavala (2011), pp. 20-21; Barbieri (2012), pp. 40-41; Cabanellas de las Cuevas (2014), p. 188; 
rencia plena sobre el derecho de imagen. ${ }^{142}$ Respecto de esto último, si bien es cierto que alguna doctrina se ha mostrado favorable a admitir la existencia de un derecho patrimonial sobre la propia imagen concebido como un derecho independiente del derecho personalísimo y que admitiría toda clase de actos de disposición, ${ }^{143}$ la calificación del derecho de imagen como un derecho de la personalidad ha sido refrendada en 2014 en el nuevo Código Civil y Comercial de la Nación, en el cual se incluye una referencia al "consentimiento para la disposición" del derecho de imagen, que todavía está abierta a interpretaciones en cuanto a su real alcance. ${ }^{144}$

\subsubsection{Brasil}

La doctrina brasilera que analiza la explotación comercial del derecho de imagen parte de la constatación básica de que nos estamos refiriendo a un derecho de la personalidad. ${ }^{145}$ Se reconoce que este derecho tiene un contenido patrimonial que significa atribuir al titular la exclusividad en el aprovechamiento económico de su imagen, lo que se manifiesta en una dimensión negativa (prohibir que otro utilice la imagen con fines comerciales o de lucro) y otra positiva (realizar negocios relativos al ejercicio de su derecho de imagen). ${ }^{146}$ De ahí que se admita la validez de los pactos relativos a la explotación comercial de la imagen, entendiendo que los mismos tienen por objeto el ejercicio del derecho por parte de su titular. ${ }^{147}$ No obstante, en tanto que estos pactos son concebidos como actos relativos al ejercicio de un derecho de la personalidad, se entiende que el consentimiento tiene el valor de ser un acto que legitima la intromisión ajena en el propio derecho de imagen, o bien como renuncia al derecho a reclamar por aquella intromisión que fue objeto de autorización, pero siempre que se respeten los límites explícitos del pacto. ${ }^{148}$

\subsubsection{Chile}

En Chile el derecho a la imagen no está mencionado expresamente en la Constitución, ni tampoco han sido regulados expresamente en las leyes especiales los aspectos relativos a su explotación comercial, lo que explica que el desarrollo haya sido impulsado mayormente por la doctrina y la jurisprudencia. ${ }^{149}$ La jurisprudencia

142 Villalba y Lipszyc (1980), p. 821; Picasso (2007), pp. 40 y 41; Gifuentes (2008); Barbieri (2012), pp. 40-41; Cabanellas de las Cuevas (2014), pp. 175, 177, 183-184 y 189. Sí se admite la cesión de ciertos elementos del derecho de imagen, por ejemplo cuando se trata del consentimiento para el registro de una marca. Ver Cabanellas de las Guevas (2014), p. 189.

143 Villalba (2006); Márouez y Calderón (2009), pp. 108 y ss.

144 Código Civil y Comercial de la Nación (2014), arts. 53 y 55.

145 Glitz y Bortolan (2017), pp. 361 y 369.

146 Glitz y Bortolan (2017), p. 368.

147 Glitz y Bortolan (2017), p. 361.

148 Glitz y Bortolan (2017), pp. 370-374.

149 Angutta (2007), p. 42; Larraín (2016), p. 127; Arancibia (2014), p. 70. La doctrina señala que existe una regulación parcial de "algunos supuestos aislados", como ser los arts. 145 I y 152 del Código de Trabajo y (aunque con dudas) el art. 161 A del Código Penal. Ver Larraín (2016, p. 128); FERRANTE (2017, pp. 144 y 145). También se ha mencionado la regulación en materia de derechos 
chilena ha considerado que la apropiación de los beneficios económicos que derivan de la utilización de la imagen de una persona requiere necesariamente obtener el consentimiento de esta última. ${ }^{150}$ En cuanto al encuadramiento jurídico de esa explotación, una parte de la jurisprudencia chilena ha entendido que debe quedar subsumida dentro de la protección constitucional del derecho de propiedad. ${ }^{151}$ Sin embargo, esta posición ha sido criticada severamente por la doctrina a causa de brindar a un derecho de la personalidad el tratamiento de los derechos reales. ${ }^{152}$ En lo que refiere a la posibilidad de celebrar negocios jurídicos que tengan por objeto la propia imagen, la doctrina se pronuncia sobre la licitud de estos pactos, en la medida en que los mismos tengan contenido obligacional (no dispositivo). ${ }^{153}$ En general se parte de que estamos ante un derecho de la personalidad que no es susceptible de ser transferido, de donde se considera que el consentimiento equivale a una renuncia a la calificación del acto de intromisión ajeno como acto ilícito en ese caso concreto, ${ }^{154}$ o bien a una causal de justificación que excluye la ilicitud. ${ }^{155}$ Sin embargo, existen algunas voces que disienten de esta consideración y postulan un derecho patrimonial autónomo. ${ }^{156}$ En cualquier caso, se niega la posibilidad de transferir o ceder el derecho de imagen. ${ }^{157}$

\subsubsection{Colombia}

La Corte Constitucional de Colombia también ha reconocido que la facultad de explotación económica del derecho se encuentra avalada por el Artículo 16 de la Carta, que hace referencia al derecho al libre desarrollo de la personalidad, lo que ha sido compartido por la doctrina. ${ }^{158}$ La doctrina ha considerado que la utilización del retrato para fines comerciales no es libre y, por lo tanto, para su reproducción se requiere la autorización previa y expresa de la persona que aparece en él o de sus causahabientes. ${ }^{159}$ De conformidad con ello, se admite ampliamente la posibilidad

de autor en el art. 34 de la Ley 17.336, aunque también con dudas porque se trataría de un reconocimiento indirecto (ver FerRante, 2017, p. 145). También se menciona el art 20 de la Ley 19.039 en materia de registro de marcas que contienen la imagen de una persona: ver AILLAPÁN (2016, p. 448).

150 González Ramírez Fernando con VTR Banda Ancha S.A.y otro. (2003); Corte de Apelaciones de Santiago, 24 de marzo de 2009.

151 Corte de Apelaciones de Santiago, Rol N 1009-2003 de fecha 8 de mayo de 2003, Corte de Apelaciones de Iquique: 12/01/2007; Corte de Apelaciones de Valparaíso, de 27/03/1997 (cit. por Nogueira, 2007, p. 267).

152 Nogueira (2007), pp. 266-270; Arancibia (2014), pp. 71 -73; Larraín (2016), pp. 131-132. Sin embargo, esta posición ofrece dudas (como postula Aillapán, 2016, pp. 450 a 452) y tiene sus detractores (como Ferrante, 2017, pp. 156 y 157).

153 Nogueira (2007), p. 274, Larraín (2017), pp. 57 y 58.

154 Nogueira (2007), p. 270.

155 LARRAÍn (2017), p. 58.

156 FERRANTe (2017).

157 LaRraín (2017), pp. 59-60.

158 Corte Constitucional, Sentencia T-090/96; en el mismo sentido: Ceballos (2011), p. 69.

159 GuZMán (2016), p. 49. 
de celebrar negocios jurídicos con relación al derecho de imagen ${ }^{160}$, aunque existe una división en cuanto a si es admisible cualquier tipo de acto de disposición ${ }^{161}$, o si solo pueden admitirse los actos de autorización (licencia) que no impliquen que el titular quede desligado de los aspectos patrimoniales sorbe su imagen ${ }^{162}$. También se sostiene en la doctrina que siempre debe existir una contraprestación por el uso comercial de la imagen de una persona, elemento que se considera como natural al contrato de explotación. ${ }^{163}$

\subsubsection{Uruguay}

Si bien el reconocimiento del derecho de imagen como un derecho de la personalidad puede encontrarse en la jurisprudencia uruguaya de mediados del siglo $\mathrm{XX},{ }^{164}$ el análisis de este tema por la doctrina comenzó en forma tardía, en el último cuarto del siglo $\mathrm{XX}^{165}$ y se desarrolló en la primera década del $2000 .{ }^{166}$ Se encuentra plenamente reconocida en doctrina la validez de los negocios jurídicos que tengan por objeto el ejercicio del derecho de imagen, ${ }^{167}$ existiendo posiciones divergentes en cuanto a si estamos ante un derecho autónomo que recae sobre la explotación patrimonial del derecho de imagen (con fuente en la ley de propiedad literaria y artística), lo que habilitaría actos de disposición traslativa del derecho, ${ }^{168} \mathrm{o}$ si estamos ante la manifestación patrimonial del derecho de la personalidad sobre la imagen, ${ }^{169}$ que en forma unánime se entiende protegido por la Constitución. ${ }^{170}$ Más allá del análisis por la doctrina, no hay jurisprudencia relevante sobre una posición u otra. Asimismo, tampoco está clara la forma en que conviviría este derecho/facultad patrimonial con el régimen establecido en la normativa sobre protección de datos personales. ${ }^{171}$

160 GuZMÁN (2016), pp. 48-50.

161 Lo que es admitido por una parte de la doctrina por aplicación analógica de las normas sobre derecho de autor: GuZMán (2016), pp. 49 y 52.

162 Ceballos (2011), p. 70.

163 GuZMán (2016), pp. 51 y 52.

164 Juzgado Letrado en lo Civil de $6^{\circ}$ Turno (França), Sent. de fecha 7/04/1954, LJU c. 3918.

165 Las primeras referencias corresponden a GamarRa (1983) e YGLesias (1987).

166 BaLsa (2001), pp. 19, 20, 22, 27-29, 47; Lamas (2004), pp. 37-39, 46, 225 y ss. Howard (2008), pp. $91,92,107$ y $108,181,184-186$.

167 Ver doctrina en nota precedente.

168 Ver Lamas (2004), cit. Balsa (2001), cit., OrdoQui (2013), pp. 324-328.

169 HOWARD (2008), quien admite todo acto de disposición, pero entiende que su alcance se encuentra acotado a eliminar la ilicitud de la intromisión y no a un veredero desplazamiento del derecho patrimonial.

170 Berdaguer Mosca (2015), pp. 188-190.

171 Sobre este aspecto: Berdaguer Mosca (2018). 


\subsection{Observaciones finales sobre el panorama de la protección patrimonial del derecho de imagen en América Latina}

$\mathrm{Al}$ margen de los distintos matices que pueden apreciarse entre el tratamiento dado en los países mencionados, el panorama general parece mayormente favorable a un modelo intermedio de protección patrimonial del derecho de imagen, conforme al cual se admite la validez de los pactos relativos al derecho de imagen que el titular celebre en beneficio de terceros, aunque restringiendo el alcance de los mismos a un contenido obligacional (entre las partes) y dispositivo, en el sentido de incluir actos de autorización o licencia que eliminen la ilicitud, o bien como fenómenos de concesión (sucesión constitutiva), mas no como actos de transferencia plena de las facultades de explotación. ${ }^{172}$

La inscripción de los países de América Latina en un modelo intermedio se ve fortalecida, por otra parte, por un conjunto de elementos que van en la línea del compromiso que vimos al considerar el marco teórico.

En tal sentido, puede mencionarse en primer lugar que la mayoría de los países exigen a nivel del derecho positivo que el consentimiento para "poner en el comercio" el retrato sea dado en forma "expresa", lo que impide que la autorización para el uso de la imagen pueda ser alegada en forma tácita, implícita o presunta. Así, puede citarse el caso de Argentina, ${ }^{173}$ Colombia, ${ }^{174}$ Costa Rica, ${ }^{175}$ Ecuador, ${ }^{176}$ México, ${ }^{177}$ Perú ${ }^{178}$ y Uruguay. ${ }^{179}$ En Brasil dicha exigencia es impuesta por la doctrina y la jurisprudencia, a pesar de no surgir de disposiciones específicas. ${ }^{180}$ En otros países, en cambio, las leyes de propiedad literaria exigen el "consentimiento" del retratado, sin otro calificativo. ${ }^{181}$

Lo anterior debe completarse con dos postulados adicionales que están alineados con el modelo de protección intermedio: (a) por un lado, la opinión generalizada en América Latina acerca de que el consentimiento para la utilización de la imagen

172 Naturalmente que el tema requiere una mayor profundización; en particular, en cuanto al régimen de transmisión mortis causa y sobre las particularidades del régimen general de responsabilidad civil en caso de intromisión ilegítima. Estos aspectos forman parte del régimen de protección y no van a ser abarcados aquí.

173 Ley (1933), art. 31.

174 Ley (1982), art. 87.

175 Ley (1982), art. 178.

176 Ley (2016), art 161.

177 Ley (1996), art 87; Ley (2006), art. 18.

178 Ley (1984), art. 15.

179 Ley (1937), art. 21.

180 Glitz y Bortolan (2017), pp. 368 y 372; Superior Tribunal de Justica: 19/12/2000.

181 Perú (1996, art 85); Paraguay (1998, art. 78); Panamá (2012, art. 37) y Honduras (1999, art. 60). 
debe interpretarse en forma estricta, tal como ocurre en Argentina, ${ }^{182}$ Brasil, ${ }^{183}$ Chile, ${ }^{184}$ Colombia ${ }^{185}$ y Uruguay, ${ }^{186}$; (b) por otro lado, aunque relacionado con lo anterior, se reconoce como aplicable un principio de especificidad, en el sentido de que la autorización se entiende dada para los exclusivos fines para los cuales fue obtenida, ${ }^{187}$ lo que explica que se entienda que el consentimiento para captación no se considere suficiente para su publicación. ${ }^{188}$

Asimismo, el derecho de revocar el consentimiento otorgado para la utilización de la imagen con fines comerciales - que, según vimos, es otro ingrediente típico de los sistemas intermedios- se encuentra expresamente reconocido en el derecho positivo de varios países de América Latina, como ser: Argentina, ${ }^{189}$ Colombia, ${ }^{190}$ Costa Rica, ${ }^{191}$ México, ${ }^{192}$ República Dominicana ${ }^{193}$ y Uruguay. ${ }^{194}$ En la mayoría de estos casos, el derecho de revocación es incluido como una potestad cuyo ejercicio por el titular supone resarcir los daños y perjuicios causados, lo que nos sitúa en sede de responsabilidad civil por hecho lícito. Fuera de los casos de reconocimiento explícito en el derecho positivo, la facultad de revocación unilateral ha sido admitida en la doctrina de Chile ${ }^{195}$ y de Brasil. ${ }^{196}$ No obstante lo anterior, cabe tener presente que el

182 El criterio de interpretación estricta deriva explícitamente del art. 55 del Código Civil y Comercial de la Nación, y es asimismo postulado por toda la doctrina: Zavala (2011), p. 21; Villalba y LipszyC (1980), p. 820; Barbieri (2012), pp. 49, 71-87; Gabanellas de las Guevas (2014), p. 177; Márouez y Calderón (2009), p. 11 1; Pizarro (1999), p. 342; NAVArro (2016), pp. 20 y 184-185. Ver jurisprudencia argentina citada por ANTEQUeRA (2012), pp. 525 a 531.

183 Glitz y Bortolan (2017), pp. 371 y 373; Superior Tribunal de Justicia: 23/10/2014. Ver jurisprudencia brasilera citada por ANTEQUERA (2012), pp. 525 y ss.

184 LaRraín (2017), p. 69. Ver jurisprudencia citada en ANTEQuera (2012), p. 534.

185 Ceballos (2011), p. 73. Ver jurisprudencia citada en Antequera (2012), p. 532.

186 Lamas (2004), p. 213.

187 Zannoni y Bíscaro (1993), pp. 108 y 115; Zavala (2011), pp. 22 y 23.

188 Antequera (2012), p. 526; Zavala (2011), p. 21; Gifuentes (2008), pp. 568-569.

189 Ley (1933), art. 31; Código Civil y Comercial (2014), art 55.

190 Ley (1982), art. 87.

191 Ley (1982), art. 178.

192 Ley (1996), art. 87. El principio de revocación no se aplica cuando la autorización para el uso de la imagen haya sido otorgada a cambio de una remuneración.

193 Ley (2000), art. 52.

$194 \operatorname{Ley}(1937)$, art. 21.

195 LARRAÍn (2017), pp. 69 y 70, aunque puntualizando que este principio aplica solo al consentimiento dado en forma unilateral, no así cuando haya sido dado bajo un contrato. La Corte Suprema privó de eficacia a una revocación ejercida luego de firmarse un contrato: Sentencia del 15 de enero de 2002, cit. por LARRAín, 2017, pp. 61 y 70 (nota 72).

196 Se admite que el titular del derecho de imagen puede revocar unilateralmente el consentimiento cuando ello obedece a razones morales o personales: GLITZ y BORTOLAN (2017), pp. 374-376, pero no existiría tal facultad para ser ejercida por razones meramente patrimoniales, en tanto ello no justifica un apartamiento de la regla pacta sunt servanda: GLITZ y BorTOLAN (2017), p. 376. 
derecho de revocar la autorización otorgada es un principio general que forma parte de la legislación nacional de la mayoría de los países en materia de protección de datos personales, siendo la armonización entre este sector y el resto de las regulaciones sobre el derecho de imagen un tema que todavía no está del todo claro.

Finalmente, en el mismo sentido del reconocimiento de un sistema intermedio apuntan las abundantes referencias que en doctrina y jurisprudencia existen en cuanto a la interpretación restrictiva de las situaciones de permiso legal, en el sentido de que las mismas son analizadas como posibles de ser invocadas en presencia de un interés general que excluye la utilización con fines comerciales. ${ }^{197}$.

197 A este respecto ver con carácter general ANTEQUERA (2012), pp. 465-68. En la doctrina argentina: Zavala (2011), p. 33; Barbieri (2012), pp. 59 y 60; Márouez - Calderón (2009), pp. 107 y 114. Para la doctrina uruguaya: Gamarra (1983) y Berdaguer Mosca (2015). 


\section{BIBLIOGRAFÍA CITADA}

AilLAPÁn, Jorge Eduardo (2016). "El derecho a la propia imagen ¿Derecho personalísimo? ¿Derecho fundamental? Precisiones terminológicas para el ordenamiento jurídico chileno", Revista Chilena de Derecho, 43(2), pp. 433-459.

Alatriste, Karla (2013). "Contrato de autorización de uso de imagen y retrato", Revista Mexicana de Derecho de Autor, Primer Semestre, Junio 2013, N 2, pp. 36 y sgtes.

Antequera Parrilli, R. (2012). "Derechos Intelectuales y Derecho a la Imagen en la Jurisprudencia Comparada", Colección de Propiedad Intelectual (dirigida por Carlos Rogel, Ed. Reus).

Arancibia, María José (2014). "Reflexionando sobre los derechos de la personalidad desde la perspectiva del derecho a la propia imagen", Revista de Derecho, Publicación de la Facultad de Derecho de la Universidad Católica del Uruguay, Año 9, No 9, Montevideo, Julio 2014, pp. 55-80.

Arroyo, Juan (2015). "Los Derechos de la Personalidad", Revista Académica de la Universidad de Salle, Año XIII, N²5, pp. 61 y sgtes.

BALsa, María (2001). "Algunas cuestiones sobre el Derecho a la propia imagen", FCU, Montevideo.

Barbieri, Pablo (2012). Derecho de imagen en el deporte (Ad.Hoc).

BAss, Ellen (2008). "A Right in Search of a Coherent Rationale - Conceptualizing Persons in a Comparative Context: The United State Right of Publicity and German Personality Rights", University of San Francisco Law Review, Vol. 42 (2007-2008), pp. 799 y ss.

Berdaguer Mosca, Javier (2015). "Utilización de la imagen con fines publicitarios y el régimen de las publicaciones libres", Revista de Doctrina y Furisprudencia de Derecho Civil, Vol. III, FGU, pp. 187 y sgtes.

Berdaguer Mosca, Javier (2018). "La imagen como dato personal", Revista de Doctrina y Jurisprudencia de Derecho Civil, Vol. VI, FGU, pp. 31 y ss.

Bergmann, Susanne (1999). "Publicity Rights in the United States and Germany: A Comparative Analysis", 19 Loyola Los Angeles Entertainment Law Review, pp. 479 y ss.

Beverly-Smith, Huw; Ohly, Ansgar, Lucas, Agnes (2005). Privacy, Property and Personality. Civil Law Perspectives on Commercial Appropriation (Cambridge University Press). 
Black, Gillian (2011). Publicity Rights and Image. Exploitation and Legal Control (Hart Publishing).

Bortolan, Gabrielle (2018). "Análise do contrato e disposição da imagem". RfLBRevista Furidica Luso-Brasileira, v. 6, pp. 737-753.

Bortolan, Gabrielle y Pascoaloto, Thais (2014). "O Direito a Imagem na perspectiva da pessoa no dierito civil contemporáneo", Revista do Instituto do Direito Brasileiro, Ano 3, No 4, pp. 3081 y sgtes.

Cabanellas De Las Guevas, Guillermo (2014). "Los derechos de imagen. Aproximación conceptual y régimen jurídico" en Derecho del Deporte (Dir. Cabanellas de las Cuevas) (Heliasta), pp. 167 y ss.

Cantero, Inés; Feinsohn, Dana, Kim, Hee-Eun; Mayr, Stefan y Rainsford, Edward (2010). "Exploiting publicity rights in the EU" - EIPIN Report, in ETH Zurich Research Collection, https://doi.org/10.3929/ethz-a-006318721

Castaldi, Carole (2008). L'explotation commerciale de l'image des personnes physiques (Université de Paris II).

Ceballos, José (2011). "Aspectos generales del derecho a la propia imagen”, La Propiedad Inmaterial, $\mathrm{N}^{\circ}$ 15, Universidad Externado de Colombia, pp. 61-83.

Cifuentes, Santos (2008). Derechos personalísimos (3rd ed., Astrea).

Gionti, Fernando (2000). La nascita del diritto sull'immagin (Giuffré).

De Castro y Bravo, Federico (1959). "Los llamados derechos de la personalidad", Anuario de Derecho Civil, pp. 1237-1275.

De Cupis, Adriano (1950). I Diritti della personalitá (Giufré).

FERRANTE, Alfredo (2017). "La protección a la imagen y su materialidad en el ordenamiento chileno", Revista Boliviana de Derecho, No 23, pp. 134-167.

FLORES, Elvia (2006). "Derecho a la imagen y responsabilidad civil", en Derecho civily romano. Culturas y Sistemas furídicos Comparados, México (web version).

Gamarra, Jorge (1983). "Derecho a la Imagen (Retrato)", Anuario de Derecho Civil Uruguayo, Vol. XIII, FCU, pp. 113-117.

Glitz, Federico \& Bortolan, Gabrielle (2017). "O contrato para disposição da imagem na perspectiva dos direitos da personalidade", Revista Fustiça do Direito, Vol. 31, No 2, pp. 358-385.

Gorosito, Alejandro (2007). "Exégesis del derecho a la propia imagen", in Lecciones y Ensayos (Revista de la Facultad de Derecho de la Universidad de Buenos Aires), № 83, pp. 253 y sgtes.

GuZmán, Diego (2016). "El contexto actual del derecho de la imagen en Colombia”, Revista La Propiedad Inmaterial No 21, Universidad Externado de Colombia, pp. 47-77.

Howard, Walter (2008). Derecho de la Persona, Vol. 1 (Universidad de Montevideo). 
Lamas, Mario (2004). Derechos de la personalidad y explotación de la apariencia humana. Estudio sobre el nombre, la imagen, la intimidad, la identidad, el honor y la reputación como derechos personales y como derechos patrimoniales (Cikato Abogados).

LARRAín, Cristián (2016). "Responsabilidad civil por vulneración del derecho a la propia imagen: análisis comparado y propuestas para el derecho chileno", $R e^{-}$ vista Chilena de Derecho Privado, No 26, pp. 119-185.

LARRAín, Cristián (2017). "Actos y contratos sobre el derecho a la imagen en el ordenamiento chileno (con referencia al derecho comparado)", Revista de Derecho Universidad Austral de Chile, Vol. $30 \mathrm{~N}^{\circ}$ 1, pp. 53 - 76.

Leaffer, M. (2007). "The Right of Publicity: A Comparative Perspective", 70 Albany Law Review, pp. 1357 y ss.

Loiseau, Gregoire (1997). "Des droites patrimoniaux de la personnalité en droit français", Revue de droite de Mc Gill, 42 R.D, pp. 319 y ss.

Márquez, José \& Calderón, Maximiliano Rafael (2009). "El Derecho a la imagen y su valor económico", Revista Crítica de Derecho Privado, N 6, pp. 99-123.

Mc Carthy, J. Thomas (2013). The Rights of publicity and privacy (Thomson Reuters).

Navarro, Juan (2016). Los derechos personalísimos (Ed. El Derecho).

Nimmer, Melville (2954). "The Right of Publicity", 19 Law and Contemporary Problems, pp. 203-223.

NogueIRA, Humberto (2007). "El derecho a la propia imagen como derecho fundamental implícito. Fundamentación y caracterización”, Revista Ius et Praxis, $\mathrm{N}^{\circ} 2$, pp. 245 y ss.

Ordoqui, Gustavo (2013). Derecho de Daños, Vol. III (Daño a la Persona) (La Ley).

Picasso, Sebastián (2007). "Nuevas fronteras del Derecho a la imagen”, Revista Crítica de Derecho Privado, $\mathrm{N}^{\circ} 4$, pp. 35 y ss.

Pino, Giorgio (2003). "Teorie e dottrine dei diritti della personalità Uno studio di meta-giurisprudenza analitica", en Materiali per una storia della cultura giuridica, 2003/1, pp. 237-274.

Priens, Corien (2006). "Property and Privacy: European Perspectives and the Commodification of our Identity", en L. Guibault \& P.B. Hugenholtz (eds.), The Future of the Public Domain (Kluwer Law), pp. 223-257.

Prosser, William (1960). "Privacy", 48 California Law Review, pp. 383-423.

Pouillet, Eugène (1908). Traité Théorique et pratique de la proprieté litterarire et artistique ( $3^{\text {éme }}$ ed., Hachette).

Resta, Giorgio (2005). Autonomia privata e diritti della personalitá - Il problema dello sfrutamento económico degli attributi della persona in prospettiva comparatistica (Biblioteca di Dirito Privato Ordinata da Pietro Rescigno, Jovene Editore).

Resta, Giorgio (2006). "I diritti della personalita", en Guido AlPa \& Giorgio Resta, Tratato di Diritto Civile (UTET). 
Resta, Giorgio (2011). "The new frontiers of personality rights and the problem of commodification: European and comparative perspectives", Tulane European and Civil Law Forum, Vol. 26, pp. 33 y ss. Available at SSRN: https://ssrn.com/ abstract $=1952695$

Resta, Giorgio (2014a). Dignitá, Persone, Mercati (Giappichelli).

Resta, Giorgio (2014b). "Personnalité, Persoenlichkeit, Personality. Comparative Perspectives on the Protection of Identity in Private Law", in L. Sмiтh, R. Tremblay \& A. Popovici, Les intraduisibles en droit civil (Thémis).

Rodrigues, Edson Moreira (2009). "Inovação jurisdicional: direito de imagem como exteriorização da personalidade, Cadernos da Escola fudicial do TRT da $4^{a}$ Região, $\mathrm{N}^{\circ} 02-2009$, pp. 113 y sgtes.

Rothman, Jennifer (2018). The Right of Publicity - Privacy reimagined for a public world (Harvard Universtity Press).

Serna, Marie (1997). L'image des personnes physiques et des biens (Collection Droite des affaires et de l'entreprise).

Vendrell Cervantes, Carles (2014). El mercado de los derechos de imagen. El consentimiento o la autorización para la intromisión en los derechos de la personalidad y la transmisión de derechos de imagen (Thomson Reuters - Aranzadi).

Vercellone, Paolo (1959). Il diritto sul proprio ritratto (Toriense).

Villalba, Carlos \& Lipszyc, Delia (2009). El derecho de autor en la Argentina (2nd ed., La Ley).

Villalba, Federico (2006). "Algunos aspectos acerca del derecho patrimonial y extrapatrimonial sobre la propia imagen", at: http://www.justiniano.com/revista_doctrina/derecho_imagen.htm

Villalba, Federico (2015). "El derecho a la imagen en el Código Civil y Comercial de la Nación", Revista Reformas Legislativas. Debates doctrinarios. Código Civil y Comercial, Año I, No 4 pp. 93 y ss.

Villalba, Carlos y Lipszyc, Delia (1980). "Protección de la propia imagen", LL 1980-C- pp. 815 y ss.

Whitman, James (2004). "The Two Western Cultures of Privacy: Dignity versus Liberty”, en Yale Law Journal, Vol. 113, April 2004, pp. 1151 y ss.

YGLesias, Arturo (1987). "Derecho a la Información”, Colección fJUS, No 30, FGU.

Zannoni, Eduardo \& Bíscaro, Beatriz (1993). Responsabilidad de los medios de prensa (Astrea).

Zavala De González, Matilde (2011). Daños a la dignidad, Vol. 2, (Astrea). 


\section{JURISPRUDENCIA GITADA}

\section{Argentina:}

Corte Suprema de Justicia de la Nación, Sentencia del 11/12/1984 (Ponzetti de Balbín, Indalia c/ Editorial Atlántida S.A.);

Corte Suprema de Justicia de la Nación, Sentencia del 15/04/1993 (Gutheim, Federico c/Alemann, Juan, Fallos 316:703);

Corte Suprema de Justicia de la Nación, Sentencia del 11/12/2007 (Herrera Ramón Santiago c/S.A. La Nación, Fallos: 330:5088),

Corte Suprema de Justicia de la Nación, Sentencia del 25/09/2001 (Menem Carlos c/Editorial Perfil y otros, Fallos: 324:2895);

Corte Suprema de Justicia de la Nación, Sentencia del 12/09/2017 (Gimbutas Carolina c/ Google Inc, Fallos: 340:1236).

\section{Bolivia:}

Tribunal Constitucional de Bolivia, Sentencia 1376/2004 del 25/08/2004.

\section{Brasil:}

Superior Tribunal de Justiça, Acórdão de 23.02.99, Quarta Turma RESP 74473/RJ.

Superior Tribunal de Justiça, Acórdão de 25.10.99, Quarta Turma no RESP 45305/ SP.

Superior Tribunal de Justiça, Decisão Monocratica 14/03/2000, ERESP 074473.

Superior Tribunal de Justiça, Recurso Especial 230306/RJ, de 18.05.2000.

\section{Colombia:}

Corte Constitucional, Sentencia T-408/1998. Expte. T 156083.

Corte Constitucional Sentencia T-546/16 del 11/10/2016 Expte. T-5.608.527

Corte Constitucional de Colombia, Sentencia T-090 de 1996 del 6 de marzo de 1996.

Corte Constitucional de Colombia, Sentencia T-471 del 6 de julio de 1999.

Corte Constitucional de Colombia, Sentencia T-405 del 24 de mayo de 2007. 


\section{Chile:}

Corte Suprema de Justicia, 9 de septiembre de 1997, Gaceta Jurídica, No 207, Santiago, septiembre, pp. 57-60.

Caroca Rodríguez Christian Antonio contra Electrónica Sudamericana Limitada (2009). Corte Suprema de Justicia, Sala $3^{\text {a }}$, Sentencia de fecha 9/06/2009, Rol No 2.5062009 .

González Ramírez Fernando con VTR Banda Ancha S.A. y otro. (2003). Corte Suprema de Justicia, Rol No 3.479-03 de 29/09/2003.

Corte de Apelaciones de Santiago, Rol No 1009-2003 de fecha 8 de mayo de 2003.

Corte de Apelaciones de Santiago, Primera Sala Sentencia del 24/03/2009, Fallo: 2.506-2009, Rol No 127-2009.

Corte de Apelaciones de Iquique, Sentencia del 12/01/2007, Rol Nº 709-2006.

Corte de Apelaciones de Valparaíso, de 27/03/1997.

\section{Estados Unidos:}

Pavesich v. New England Life Ins. Co. 50 S.E. 68 (Ga. 1905).

Haelan Laboratories, Inc. v. Topps Chewing Gum, Inc, 202 F.2d 866 (2d Cir. 1953), US Court of Appeals for the Second Circuit.

Zacchini v. Scripps-Howard Broadcasting Co., 433 U.S. 562 (1977).

\section{Francia:}

Tribunal Civil de la Seine 16-6-1858, Dalloz, 1858, III, p. 62.

\section{México:}

Suprema Corte de Justicia de la Nación, Fallo del Tribunal Pleno de fecha 6/01 /2009.

\section{Puerto Rico:}

Tribunal Supremo de Puerto Rico, Colón v. Romero Barceló (112 D.P.R. 573 (1982).

Tribunal Supremo de Puerto Rico (Bonilla Medina v. PNP, 140 DPR 294 (1996)).

Tribunal Supremo de Puerto Rico, Vigoreaux Lorenzana v. Quizno’s Sub, Inc 2008 T.S.P.R. 38.

\section{República Dominicana:}

Cuarta Sala de la Cámara Civil y Comercial del Juzgado de Primera Instancia del

Distrito Nacional, Sentencia 0659/2008 de fecha 30-7-2008. 
Cámara Civil y Comercial de la Corte de Apelación del Distrito Nacional, Segunda Sala, Sentencia 310-2009 de fecha 5/06/2009, Expediente 026-03-08-00671.

\section{Uruguay:}

Tribunal de Apelaciones en lo Civil, $6^{\circ}$ Turno, Sentencia No 260/97 del 5/12/97, LJU, caso 13.475;

Tribunal de Apelaciones en lo Civil, $2^{\circ}$ Turno, Sentencia 20/2011, ADGU XLII pp. 76 у LJU c. 16.290;

Tribunal de Apelaciones en lo Civil, $4^{\circ}$ Turno, Sentencia No 39/2012 del 20/02/2012, pub. en Revista de Doctrina y Jurisprudencia de Derecho Civil, t. 1 (2013), c. 36. 


\section{NORMAS GITADAS}

\section{Alemania:}

Código Civil BGB (1900) - Bürgerliches Gesetzbuch (BGB).

Ley del 9 de enero de 1907 sobre Derechos de Autor en Obras Artísticas y Fotografía - Gesetz betreffend das Urheberrecht an Werken der bildenden Künste und der Photographie.

\section{Argentina:}

Ley 11.723 (1933) - Régimen Legal de la Propiedad Intelectual.

Código Civil y Comercial de la Nación Aprobado por Ley 26.994 (2014).

Ley 25.326 de Datos Personales (2000).

\section{Bolivia:}

Constitución Política del Estado (2009).

Código Civil aprobado por DL 12760 de 06/08/1975.

\section{Brasil:}

Código Civil Brasilero de 1916 - Ley No 3.701 del 1/01/1916, derogado por Ley $\mathrm{N}^{\circ} 10.406$ de 2002.

Constitución Política de la República Federativa de Brasil (1988).

Código Civil Brasilero de 2002: Ley N 10.406 del 10/01/2002.

Lei de Direitos Autorais - Lei No 9.610, de 19 de fevereiro de 1998.

Lei No 9.615 del 24/03/1998 ("Lei Pelé").

\section{Colombia:}

Ley No 86/1946 del 26/12/1946.

Constitución Política de Colombia (1991).

Ley No 23/1982 sobre Derechos de Autor (1982).

Ley 1581 de 2012 (Datos Personales). 


\section{Costa Rica:}

Código Civil - Ley número XXX de 19 de abril de 1885, reformado por ley $\mathrm{N}^{\mathrm{o}} 7600$ del 2 de mayo de 1996.

Ley No 6683 - Ley de Derecho de Autor y Derechos Conexos (1982).

\section{Chile:}

Ley 19.628 (1999) de Datos Personales.

\section{Ecuador:}

Constitución de la República del Ecuador del 20 de octubre de 2008.

Código de la Economía Social de los Conocimientos, Creatividad e Innovación, del 9 diciembre 2016.

\section{El Salvador:}

Constitución Política de El Salvador de 1983.

Ley de Propiedad Intelectual de 14 de julio de 1993 (modificada hasta el Decreto Legislativo $\mathrm{N}^{\circ} 611$, de 15 de febrero de 2017).

\section{España:}

Constitución Española (1978).

Ley Orgánica 1/1982, de 5 de mayo, sobre protección civil del derecho al honor, a la intimidad personal y familiar y a la propia imagen (1982).

\section{Francia:}

Loi No 70-643 du 17 juillet 1970, tendant à renforcer la garantie des droits individuels des citoyens.

\section{Guatemala:}

Ley del Derecho de Autor y Derechos Conexos del 21 de 1998.

\section{Honduras:}

Constitución de la República de Honduras de 1982.

Ley del Derecho de Autor y de los derechos conexos de 1999. 


\section{Italia:}

Regio decreto legge 7 novembre 1925 n. 1950. Disposizioni sul diritto di autore.

L. 22 aprile 1941, n. 633 - Protezione del diritto d'autore e di altri diritti connessi al suo esercizio (1941).

R.D. 16 marzo 1942, n. 262 Approvazione del testo del Codice Civile (1942).

\section{México:}

Ley Federal de Derechos de autor del 24/12/1996

Reglamento de la Ley Federal de Derechos de Autor 22/05/1998.

Ley de responsabilidad civil para la protección del derecho a la vida privada, el honor y la propia imagen en el Distrito Federal, 19 de mayo de 2006.

Ley Federal de Datos Personales (2010).

\section{Panamá:}

Ley 64 de 10 de Octubre de 2012 Sobre Derecho de Autor y Derechos Conexos. Ley 3 de 1994 - Código de Familia.

\section{Paraguay:}

Constitución de la República del Paraguay del 20 de junio de 1992.

Ley 94/1951 del 31 de marzo de 1951 sobre creaciones científicas, literarias y artísticas.

Ley No 1328/1998 de Derecho de Autor y Derechos Conexos.

\section{Perú:}

Constitución Política del Perú de 1993.

Ley sobre Derecho de autor - Decreto Legislativo No 822 (1996).

Código Civil - Decreto Legislativo No 295 del 25 de julio de 1984.

Ley 29.733 (2011) - Datos Personales.

\section{Portugal:}

Constitução da República Portuguesa (1976).

Código Civil - DL No 47344/66, de 25/11/1966. 


\section{Puerto Rico:}

Ley del Derecho sobre la Propia Imagen - Ley Núm. 139 de 13 de julio de 2011.

\section{República Dominicana:}

Constitución Política de la República Dominicana del 26 de enero de 2010.

Ley $N^{\circ}$ 65-00, de 21 de agosto de 2000, de Derecho de Autor.

\section{Uruguay:}

Ley No 9.739 - Ley de Propiedad Literaria y Artística de 17/12/1937.

Ley No 18331 - Ley de Datos Personales (2008).

\section{Venezuela:}

Constitución de la República Bolivariana de Venezuela de 1999. 